\title{
ANÁLISE DE ÁGUA SUPERFICIAL PARA CONSUMO HUMANO EM UM MUNICÍPIO DO RIO GRANDE DO SUL
}

\author{
Fábio Fernandes Koch ${ }^{1}$, Carla Kauffmann ${ }^{2}$, Jonas Bernardes Bica ${ }^{3}$, Fernanda Scherer Adami ${ }^{4}$, \\ João Francisco Stevens ${ }^{5}$, Claudio Luiz Eckhard ${ }^{6}$, Luana Gabriela Marmitt ${ }^{7}$, \\ Eniz Conceição de Oliveira ${ }^{8}$
}

Resumo: O objetivo do presente estudo foi identificar a qualidade da água destinada ao consumo humano em um município gaúcho relacionando parâmetros físico-químicos e microbiológicos em conformidade com a Portaria do Ministério da Saúde (MS) no 2914, de 12 de dezembro de 2011. As amostras de água foram submetidas a análises físico-químicas: potencial hidrogeniônico, cor, turbidez, condutividade, dureza, carbono orgânico, carbono inorgânico, nitrogênio, fluoreto, cloreto, nitrato e sulfato e análises microbiológicas: contagem total de heterotróficos, de coliformes totais e de coliformes termotolerantes. Todas as amostras apresentaram resultado de turbidez, cor, coliformes totais, coliformes termotolerantes e bactérias heterotróficas acima do padrão legal vigente. Conclui-se com este estudo que as águas testadas apresentam-se inadequadas ao consumo humano.

Palavras-chave: Águas de superfícies. Microbiologia da água. Poluentes da água. Saúde pública.

1 Tecnólogo em gestão ambiental, mestre em ambiente e desenvolvimento pela Univates e Coordenador Técnico de Processos da empresa Solar Comércio e Agroindústria LTDA.

2 Farmacêutica, mestre em Ciências Farmacêuticas pela UFRGS e docente da Univates.

3 Biólogo, mestre em ambiente e desenvolvimento pela Univates.

4 Nutricionista, doutora em ambiente e desenvolvimento pela Univates e docente da Univates.

5 Químico industrial, mestre em ambiente e desenvolvimento pela Univates e empresário.

6 Administrador, mestre em ambiente e desenvolvimento pela Univates e consultor de empresas.

7 Graduanda do curso de Química Industrial da Univates.

8 Química, doutora em Química pela UFRGS, docente do Programa de Pós-graduação em Ambiente, Desenvolvimento, Ensino e Ensino de Ciências Exatas da Univates. 


\title{
SURFACE WATER ANALYSIS USED FOR HUMAN CONSUMPTION IN A RIO GRANDE DO SUL COMMUNITY
}

\begin{abstract}
The aim of this study was to identify the quality of water intended for human consumption, in a town of Rio Grande do Sul, relating physical, chemical and microbiological parameters in accordance with the Ordinance of the Ministry of Health $(\mathrm{MOH}) \mathrm{n}^{\circ} 2914$, of December $12^{\text {th }}, 2011$. Water samples were subjected to physical and chemical analysis by hydrogenionic potential, color, turbidity, conductivity, hardness, organic carbon, inorganic carbon, nitrogen, fluoride, chloride, nitrate and sulfate and microbiological analysis to the total count of heterotrophic, total coliform and thermotolerant coliform. All samples produced turbidity, color, total coliform, thermotolerant coliform and heterotrophic bacteria above the current legal standard. It was concluded in this study that that tasted water was inadequate for human consumption.
\end{abstract}

Keywords: Surface waters. Water microbiology. Human consumption. Water pollutants. Potability. Public health.

\section{INTRODUÇÃO}

O fornecimento de água sem riscos para a saúde humana, de acordo com a Constituição Brasileira de 1988, é uma responsabilidade do poder público. Neste sentido, e de forma a melhorar a qualidade da água destinada ao consumo humano, diversos programas governamentais vinculados ao Ministério da Saúde, implantados através da Secretaria de Vigilância em Saúde, contribuíram para minimizar seus danos à saúde da população nas últimas décadas (BRASIL, 2009).

No que diz respeito à qualidade da água para consumo humano, a vigilância em saúde ambiental consiste no conjunto de ações adotadas pelas autoridades de saúde pública para garantir à população o acesso à água com qualidade compatível com o padrão de potabilidade estabelecido na legislação vigente, com vistas à promoção da saúde e a qualidade de vida da população (BRASIL, 2004). Tais ações têm por referência legal básica a Portaria no 2914 de 12 de dezembro de 2011, emitida pelo Ministério da Saúde, a qual especifica água potável como sendo aquela para consumo humano cujos parâmetros microbiológicos, físicos, químicos e radioativos atendam ao padrão de potabilidade e que não ofereça riscos à saúde (BRASIL, 2011).

No entanto, o uso de água de fontes ainda é uma realidade em muitas localidades brasileiras, segundo dados do censo do Instituto Brasileiro de Geografia e Estatística (IBGE) (2000), 16,7 \% da população brasileira empregava água oriunda de poço ou nascente existente na propriedade, sendo que no estado do Rio Grande do Sul esta parcela alcançava 17,4\%. Ainda, segundo IBGE (2010), 5,77\% da população brasileira não tem acesso à água canalizada e $11,5 \%$ da população que possui água canalizada não a recebe a partir da rede geral de distribuição. 
O constante monitoramento da qualidade da água bruta e tratada fornece dados favoráveis para a correta gestão e redução dos riscos para a saúde pública, visto a diversidade de enfermidades transmitidas pela água (SANTOS et al., 2010). Em termos gerais, os maiores riscos estão associados à ingestão de água contaminada com fezes humanas e/ou animais. Tal contaminação decore de ações antrópicas junto a mananciais, ausência de adequado tratamento dos dejetos humanos e animais, além da conservação da malha de distribuição de água (CABRAL, 2010). Neste sentido, a água não potável é um importante fator no processo de ocorrências de doenças diarreicas, e a forma de acessá-la é determinante na redução de agravos (LUNA et al., 2011). Entre as principais doenças relacionas a ingestão de água contaminada, destaca-se a cólera, febre tifoide, hepatite $\mathrm{A}$, doenças gastrintestinais e diarreicas agudas, além de parasitas como a Ameba, Giárdia, Crystosporitum e Cyclospora(DDTHA/CVE, 2009).

$\mathrm{O}$ enquadramento de águas quanto a sua potabilidade, no que diz respeito à qualidade microbiológica, determina que microrganismos patogênicos tal como coliformes totais, Escherichia coli ou coliformes termotolerantes devem estar ausentes em alíquotas de $100 \mathrm{~mL}$, bem como estipula o limite de 500 unidades formadoras de colônia (UFC) por ml para microrganismos heterotróficos (BRASIL, 2011).

No Brasil, ainda, ocorrem casos de tracoma, lepra, esquistossomose, leishmaniose visceral, ancilostomíase, dengue, ascaridíase, leishmaniose cutânea, tricuríase, leptospirose, oncocercose (HOTEZ, 2008). Esta realidade nos faz lembrar o personagem Jeca Tatu, criado e popularizado pelo escritor Monteiro Lobato no início do século passado. Jeca Tatu era o símbolo do caboclo indolente e sem iniciativa que habitava o interior do país em condições sanitárias deploráveis e, por isso mesmo, era acometido de várias doenças tropicais, em especial as verminoses, que sugavam sua energia e o tornava suscetível a outras doenças (PALMA, 2012).

$\mathrm{O}$ uso de águas de poços ou nascentes é uma característica comum em áreas rurais, que pode ser relacionada não apenas a um fator estrutural, mas também cultural. A água superficial é definida como a parcela de água armazenada ou fluindo sobre a superfície, que está continuamente interagindo com a atmosfera e com o solo, dependendo de uma série de fatores, como climáticos, topográficos, cobertura vegetal além das propriedades hidráulicas do solo, pode ter sua ocorrência distribuída espacialmente ou temporariamente, como por exemplo, em rios ou lagos (CHOW et al., 1988; KOLLET; MAXWELL, 2006).

Considerando que o emprego de águas superficiais, ainda, é prática comum em algumas localidades no interior do estado do Rio Grande do Sul e que a qualidade desta água pode relacionar-se a riscos à saúde publica, o presente trabalho objetivou identificar a qualidade da água destinada ao consumo humano em um município gaúcho relacionando parâmetros físico-químicos e microbiológicos em conformidade com a Portaria do Ministério da Saúde (MS) no 2914, de 12 de dezembro de 2011. 


\section{MÉTODOS}

A pesquisa foi realizada em um município do estado do Rio Grande do Sul, selecionado por conveniência. A área total do município estudado é de $125,176 \mathrm{Km}^{2}$, este possui uma população de 4.068 habitantes, sendo que 2523 vivem na zona rural e 1545 na zona urbana (IBGE, 2010). No município amostrado, 36,2\% da população era abastecida pela rede geral, $33,5 \%$ por poço ou nascente e $30,3 \%$ por outras formas (IBGE, 2000).

O município pesquisado localiza-se no Vale do Taquari, região constituída por 36 municípios, que se localiza na zona central do Rio Grande do Sul, e envolve uma área de 4.821,1 Km², ao longo do rio Taquari e seus afluentes, na extensão compreendida entre os municípios de Arvorezinha e Taquari, estendendo-se, a oeste, até os municípios de Progresso e Sério e, a leste, até Poço das Antas e Paverama. A região possui 327.822 habitantes, em sua maioria de origem alemã, italiana ou açoriana (UNIVATES, 2012).

Nos últimos 40 anos, o perfil socioeconômico e demográfico da região tem sofrido grandes alterações em virtude da intensa industrialização observada, bem como pelo desenvolvimento do comércio e do setor de serviços. Em 1970, 74,27\% da população viviam no meio rural enquanto, atualmente, observa-se uma situação oposta com mais de $73 \%$ dos indivíduos residindo na zona urbana. Nos pequenos municípios, cuja população é essencialmente rural, a agropecuária é a principal atividade econômica, enquanto os municípios maiores destacam-se pelas atividades ligadas à indústria e ao setor de serviços e comércio, concentrando sua população na zona urbana (UNIVATES, 2012).

\section{Coleta das amostras de água}

As amostras de água foram coletadas em duplicata em propriedades localizadas na área rural do município, no mês de julho de 2012. A seleção das propriedades atendeu o critério de conveniência. A equipe de coleta solicitou autorização do proprietário para análise da água, caracterizou a propriedade e identificou o ponto de coleta mais conveniente.

As áreas de coleta, na sua grande maioria, são utilizadas na produção de culturas anuais e criação de animais para a subsistência das famílias. Em observação aos relevos, notou-se que os mesmos apresentavam-se em áreas íngremes de encostas de morros. Quanto às fontes de coleta de água, não observou-se trato cultural quanto a sua preservação, sendo possível verificar a criação de animais em áreas adjacentes superiores aos locais de coleta. Quanto a vegetação observada, verificou-se que os residentes não apresentaram preocupação quanto a preservação da vegetação nativa, principalmente na área de entorno das fontes de água.

De acordo com os proprietários entrevistados, as fontes de analisadas são utilizadas tanto para consumo humano bem como para dessedentação animal. Todas as coletas 
foram realizadas seguindo os procedimentos recomendados pelo Standard Methods for the Examination of Water and Wastewater (2005) e pela Instrução Normativa no 62 de 26/08/2003 DAS/MAPA (APHA, 2005)(BRASIL, 2003).

\section{Análises físico-químicas}

As amostras de água foram submetidas à análise dos seguintes parâmetros físicoquímicos: potencial Hidrogeniônico $(\mathrm{pH})$, cor, turbidez, condutividade, dureza, carbono orgânico, carbono inorgânico, nitrogênio, fluoreto, cloreto, nitrato e sulfato.

Os ensaios de $\mathrm{pH}$, cor, turbidez, condutividade, dureza, carbono inorgânico, carbono orgânico e nitrogênio foram realizados no Laboratório de Química da Univates de Lajeado, RS. As análises de fluoreto, cloreto, nitrato e sulfato foram realizadas no Laboratório do Pólo de Desenvolvimento Regional do Vale Taquari. Todos os procedimentos realizados seguiram a metodologia proposta pelo Standard Methods for the Examination of Water and Wastewater (2005) (APHA, 2005).

$\mathrm{O}$ ensaio de $\mathrm{pH}$ foi executado em um pHmetro Metrohm modelo $827 \mathrm{pH}$ LAB. $\mathrm{Na}$ análise da cor utilizou-se de um colorímetro marca Digimed, modelo DM-Cor. Para análise da turbidez empregou-se um turbidímetro marca Digimed, modelo DMTV. As amostras tiveram sua condutividade determinada com o auxílio de um módulo de condutividade Metrohar 856. Cabe-se salientar que todas estas análises foram realizadas em triplicata.

A dureza da água foi obtida pela análise de titulometria de complexação com EDTA com cada uma das amostras, realizada em triplicata.

$\mathrm{Na}$ determinação das quantidades de carbono orgânico e inorgânico presentes nas amostras foi utilizado um analisador da marca Shimadzu, modelo TOC-V. O teste de nitrogênio foi realizado em um equipamento Shimadzu, modelo TMN-1.

As análises de fluoreto, cloreto, nitrato e sulfato foram realizadas em um equipamento Compact, modelo IC PRO 881, utilizando uma coluna METROSEP A SUPP 5, com a temperatura da amostra de $30^{\circ} \mathrm{C}$.

\section{Análises microbiológicas}

As análises microbiológicas (determinação da contagem total de heterotróficos, de coliformes totais e de coliformes termotolerantes) foram realizadas de acordo com a metodologia descrita na Instrução Normativa no 62 de 26/08/2003 DAS/MAPA (BRASIL, 2003). 


\section{RESULTADOS E DISCUSSÃO}

As amostras de água coletada no município pesquisado, são empregadas para consumo humano e para dessedentação animal. As propriedades analisadas localizamse em zona rural do município. Em todas as propriedades, a nascente está em ponto mais alto que o local de coleta, porém, pode-se verificar que, também, todas as propriedades possuem criação de animais (bovinos, aves) e estas se localizam na área da adjacentemente superior à nascente, propiciando/facilitando possível contaminação da fonte com dejetos.

Tabela 1 - Caracterização dos locais de coleta das amostras de águas superficiais em município do interior do Rio Grande do Sul

\begin{tabular}{|c|c|c|c|c|}
\hline Amostra & $\begin{array}{c}\text { Cota } \\
\text { altimétrica }(\mathrm{m})\end{array}$ & $\begin{array}{c}\text { Finalidade do consumo } \\
\text { da água relatada pelo } \\
\text { proprietário }\end{array}$ & $\begin{array}{c}\text { Atividades desenvolvidas } \\
\text { na propriedade }\end{array}$ & $\begin{array}{c}\text { Propriedade } \\
\text { abastecida pela } \\
\text { rede geral } \\
\end{array}$ \\
\hline 1 & 65 & $\begin{array}{c}\text { Consumo humano e } \\
\text { dessedentação de animais }\end{array}$ & $\begin{array}{l}\text { Monoculturas anuais e } \\
\text { criação de animais }\end{array}$ & $\begin{array}{c}\text { Sem abastecimento } \\
\text { público }\end{array}$ \\
\hline 2 & 57 & Dessedentação de animais & $\begin{array}{l}\text { Monoculturas anuais e } \\
\text { criação de animais }\end{array}$ & $\begin{array}{c}\text { Recebe } \\
\text { abastecimento de } \\
\text { rede pública }\end{array}$ \\
\hline 3 & 91 & $\begin{array}{c}\text { Consumo humano e } \\
\text { dessedentação de animais }\end{array}$ & $\begin{array}{c}\text { Monoculturas anuais, } \\
\text { fumo e criação de } \\
\text { animais }\end{array}$ & $\begin{array}{c}\text { Sem abastecimento } \\
\text { público }\end{array}$ \\
\hline 4 & 381 & Dessedentação de animais & $\begin{array}{l}\text { Monoculturas de verão e } \\
\text { criação de animais }\end{array}$ & $\begin{array}{c}\text { Recebe } \\
\text { abastecimento de } \\
\text { rede pública } \\
\end{array}$ \\
\hline 5 & 446 & $\begin{array}{c}\text { Consumo humano e } \\
\text { dessedentação de animais }\end{array}$ & $\begin{array}{c}\text { Monoculturas anuais e } \\
\text { criação de animais }\end{array}$ & \begin{tabular}{|c|}
$\begin{array}{c}\text { Sem abastecimento } \\
\text { público }\end{array}$ \\
\end{tabular} \\
\hline 6 & 519 & Dessedentação de animais & $\begin{array}{c}\text { Monoculturais anuais, } \\
\text { criação de animais para } \\
\text { subsistência e peixe para } \\
\text { comércio }\end{array}$ & $\begin{array}{l}\text { Recebe } \\
\text { abastecimento de } \\
\text { rede pública }\end{array}$ \\
\hline 7 & 101 & Dessedentação de animais & Moradia e Comércio & \begin{tabular}{|c|} 
Recebe \\
abastecimento de \\
rede pública \\
\end{tabular} \\
\hline 8 & 124 & $\begin{array}{c}\text { Consumo humano e } \\
\text { dessedentação de animais }\end{array}$ & $\begin{array}{l}\text { Monoculturas anuais e } \\
\text { criação de animais }\end{array}$ & $\begin{array}{c}\text { Sem abastecimento } \\
\text { público }\end{array}$ \\
\hline
\end{tabular}

Fonte: dos autores.

$\mathrm{O}$ pH indica a acidez, neutralidade ou alcalinidade da água, sendo influenciado pela concentração de gás carbônico presente na água e por elevadas concentrações de ácidos orgânicos dissolvidos na água, que reduzem o $\mathrm{pH}$, entre outros fatores (ESTEVES, 1998; APHA, 2005). As amostras de água apresentaram $\mathrm{pH}$ variando de 6,35 (amostra 5) a 7,59 (amostra 1) (TABELA 2), estando de acordo com o observado por Maier (1978), o qual verificou que em ambientes lóticos brasileiros, o pH é próximo a neutralidade. 
Tabela 2 - Resultado das análises físico-químicas das águas superficiais em um município do interior do Rio Grande do Sul

\begin{tabular}{|c|c|c|c|c|c|c|c|c|c|}
\hline Amostra & $\begin{array}{c}\text { Carbono } \\
\text { Orgânico } \\
(\mathrm{mg} / \mathrm{L})\end{array}$ & $\begin{array}{c}\text { Carbono } \\
\text { Inorgânico } \\
(\mathrm{mg} / \mathrm{L})\end{array}$ & $\begin{array}{c}\text { Carbono } \\
\text { Total } \\
(\mathrm{mg} / \mathrm{L})\end{array}$ & $\begin{array}{c}\text { Nitrogênio } \\
(\mathrm{mg} / \mathrm{L})\end{array}$ & $\mathrm{pH}$ & $\begin{array}{l}\text { Condutividade } \\
(\mu \mathrm{S} / \mathrm{cm})\end{array}$ & $\begin{array}{l}\text { Turbidez } \\
\text { (uT) }\end{array}$ & $\begin{array}{c}\text { Colorometria } \\
(\mathrm{uH})\end{array}$ & $\begin{array}{l}\text { Dureza } \\
(\mathrm{mg} / \mathrm{L})\end{array}$ \\
\hline & & & & & & & $\begin{array}{l}\text { VMP: } \\
5 \mathrm{uT}\end{array}$ & $\begin{array}{l}\text { VMP: } \\
15 \mathrm{uH}\end{array}$ & $\begin{array}{c}\mathrm{VMP}: \\
500 \mathrm{mg} / \mathrm{L}\end{array}$ \\
\hline 1 & 4,11 & 33,35 & 37,46 & 3,05 & 7,59 & 256,76 & 9,78 & 27,96 & 118,00 \\
\hline 2 & 2,55 & 24,22 & 26,77 & 1,08 & 7,27 & 151,68 & 25,14 & 98,80 & 76,47 \\
\hline 3 & 3,39 & 18,05 & 21,44 & 0,74 & 7,25 & 106,80 & 40,83 & 134,33 & 54,13 \\
\hline 4 & 1,67 & 3,52 & 5,19 & 1,29 & 7,36 & 36,08 & 5,06 & 16,46 & 10,33 \\
\hline 5 & 2,86 & 6,85 & 9,71 & 1,35 & 6,35 & 33,56 & 17,01 & 57,96 & 7,87 \\
\hline 6 & 3,21 & 2,69 & 5,90 & 2,78 & 6,66 & 39,48 & 69,20 & 115,33 & 8,87 \\
\hline 7 & 3,53 & 19,84 & 23,36 & 1,50 & 7,18 & 150,92 & 23,96 & 87,96 & 74,33 \\
\hline 8 & 2,89 & 26,26 & 29,15 & 11,24 & 6,67 & 218,50 & 37,76 & 101,00 & 110,60 \\
\hline
\end{tabular}

Parâmetros de referência: Portaria MS no 2914 de 12/12/2011

VMP: Valor Máximo Permitido

Fonte: dos autores.

A turbidez é a propriedade que indica a transparência de um líquido devido à presença de materiais em suspensão ou material coloidal, enquanto que o parâmetro cor indica a coloração da água e resulta primariamente da presença ou não de material orgânico. Partículas quando suspensas na água dão uma aparência de cor. O termo cor é usado significando cor verdadeira, isto é a cor da água da qual foi removida a turbidez (APHA, 2005).

A Portaria MS no 2914, de 12/12/2011, estabelece Valor Máximo Permitido (VMP) para turbidez e cor, respectivamente, $5 \mathrm{uT}$ e $15 \mathrm{uH}^{3}$. Todas as amostras analisadas apresentaram valores superiores ao estabelecido pela legislação vigente, ou seja, não atendem ao critério de potabilidade quanto à turbidez e cor (TABELA 2). Estes parâmetros se correlacionam, sendo que quanto maior a turbidez da amostra, mais intensa sua coloração.

Turbidez e coloração podem estar relacionadas à presença de material orgânico na água e/ou sais dissolvidos, como ferro e manganês. Esta relação pode ser observada para as amostras 3 e 6, que apresentaram índice elevado de carbono orgânico, respectivamente, 3,39 e $3,21 \mathrm{mg} / \mathrm{L}$, assim como turbidez e cor em valores superiores aos permitidos (TABELA 2). Tal condição também foi observada por Scorsafawa et al. (2010), quando foram avaliados poços e minas do Estado de São Paulo.

O material orgânico presente na água pode ser oriundo de um conjunto de substâncias provenientes da excreção, secreção e de processos de decomposição de organismos, incluindo principalmente proteínas, aminoácidos, ácidos graxos e 
compostos húmicos, em variações de concentração que dependem das condições físicas do meio aquático e da bacia de drenagem (MANTOVANI, 2010).

A presença de carbono orgânico com valores elevados, tal como identificado nas amostras 3, 6 e 8, pode ser um indicativo da presença de ácidos húmicos e fúlvicos dissolvidos na água, tal como relatado por outros autores que relacionam a presença de ácidos orgânicos como sendo os principais responsáveis pela coloração marromamarelada da água, visto que as mesmas amostras também apresentaram resultados de cor verdadeira e turbidez elevados. No entanto, outras substâncias como areia e argila, elevada concentração de ferro e manganês podem influenciar na turbidez e coloração da água (RAMOS, 2010).

Em amostras de águas, o carbono inorgânico apresenta-se nas formas de dióxido de carbono, ácido carbônico e suas formas dissociadas, ou em alguns casos na forma de minerais como calcita. Já o carbono orgânico é em grande parte originário pela matéria orgânica presente na água, decorrente do solo ou da lixiviação de dejetos humanos e ou de animais presentes no entorno do ponto de captação (CLEMENTINO et al., 2008).

Em todas as amostras avaliadas, percebe-se que a maior fração do carbono total é oriunda de fonte inorgânica, ou seja, apresenta-se como carbono inorgânico possivelmente decorrente da presença de carbonatos de cálcio e sódio dissolvidos, transferência de gás carbônico presente no solo e da interface ar-água, como tal descrito por Mortatti et al. (2006).

A condutividade elétrica é a medida da capacidade de uma solução em conduzir corrente elétrica. Esta capacidade é diretamente proporcional ao teor de sólidos dissolvidos sob a forma de íons, além da temperatura da amostra. Os íons mais responsáveis pelos valores de condutividade elétrica são os chamados macronutrientes, como cálcio, magnésio, potássio, e sódio, além de carbonato, sulfato e cloreto (ZILLMER, VARELLA, ROSSETE, 2006).

Nas amostras 1 e 8 , foi verificada condutividade elevada, com resultados expressos acima de $200 \mu \mathrm{S} / \mathrm{cm}$. Também pode ser notado, que as mesmas amostras apresentaram resultados elevados de dureza. Sendo a dureza decorrente de compostos de cálcio e magnésio, decorre-se que a elevada condutividade pode estar atrelada à presença de íons de cálcio e magnésio.

A dureza da água deve-se principalmente à presença de compostos de cálcio e magnésio, em geral sob a forma de carbonatos, sulfatos e cloretos. De acordo com a UFV (2008) águas com dureza total inferior a $50 \mathrm{mg} / \mathrm{L} \mathrm{CaCO}_{3}$ são do tipo brandas ou moles, de 50 a $100 \mathrm{mg} / \mathrm{L} \mathrm{CaCO}_{3}$ são pouco duras, de 100 a $200 \mathrm{mg} / \mathrm{L} \mathrm{CaCO}_{3}$ são duras e acima de $200 \mathrm{mg} / \mathrm{L} \mathrm{CaCO}_{3}$ são muito duras.

De acordo com a Portaria MS no 2914, de 2011, o VMP em águas potáveis é de $500 \mathrm{mg} / \mathrm{L}$ de dureza total, sendo que as águas amostradas se apresentaram em conformidade com o padrão legal. Conforme a classificação proposta, as amostras 4 , 
5 e 6 são classificadas como brandas ou moles, amostras 2, 3 e 7 são pouco duras, e amostras 1 e 8 como duras. Também se pode notar a correlação existe entre a dureza, a condutividade e o carbono inorgânico nas amostras 1,2, 3, 7, 8. Tal correlação deriva da presença em comum de sais de cálcio e magnésio, principalmente na forma de carbonatos e sulfatos, conforme determinações descritas anteriormente.

O nitrogênio apresenta-se em diversas formas e estados de oxidação. No meio aquático pode ser encontrado como nitrogênio orgânico, nitrogênio amoniacal, nitrito e nitrato, caracterizando um fator importante da qualidade da água por se um indicativo de contaminação por atividades antrópicas, contaminação do aquífero e de possíveis condições higiênico-sanitárias insatisfatórias (ALABURDA, NISHIHARA, 1998). Tal preocupação quanto à presença em águas deriva dos efeitos tóxicos aos seres humanos. Teores de nitrato acima de $10 \mathrm{mg} / \mathrm{L}$ podem provocar a metahemoglobina infantil (doença do sangue azul) e a produção de nitrosaminas e nitrosamidas, ambas carcinogênicas (CABRAL, 2010).

Das amostras analisadas, obteve-se resultado mais significativo para a amostra 8 $(11,24 \mathrm{mg} / \mathrm{L})$, enquanto a amostra $3(0,74 \mathrm{mg} / \mathrm{L})$ apresentou menor quantificação de nitrogênio total (TABELA 2). Em concordância com este resultado, o teor de nitrato presente na amostra 8 apresentou-se elevado, $9,352 \mathrm{mg} / \mathrm{L}$, porém, inferior ao VMP $(10 \mathrm{mg} / \mathrm{L})$ pela legislação vigente (TABELA 3). No entanto, considerando que na propriedade onde foi realizada a coleta desta amostra, a água é empregada também para consumo humano, este resultado é preocupante. Soma-se o fato que a propriedade localiza-se numa encosta estando, portanto, sua fonte de água sujeita à contaminação por dejetos animais e humanos advindos das propriedades localizadas em porções adjacentes superiores ao local da coleta, o que poderia explicar os valores encontrados de nitrogênio total e nitrato. 
Tabela 3 - Resultado da análise de íons presentes em amostras de águas superficiais em município do interior do Rio Grande do Sul

\begin{tabular}{c|r|r|r|r}
\hline \multirow{2}{*}{ Amostra } & Fluoreto (mg/L) & \multicolumn{1}{c}{ Cloreto (mg/L) } & \multicolumn{1}{c}{ Nitrato (mg/L) } & \multicolumn{1}{c}{ Sulfato (mg/L) } \\
\cline { 2 - 5 } & VMP: $1,5 \mathrm{mg} / \mathrm{L}$ & VMP: $250 \mathrm{mg} / \mathrm{L}$ & VMP: $10 \mathrm{mg} / \mathrm{L}$ & VMP: $250 \mathrm{mg} / \mathrm{L}$ \\
\hline $\mathbf{1}$ & 0,165 & 4,797 & 2,707 & 8,675 \\
\hline $\mathbf{2}$ & 0,137 & 3,067 & 0,397 & 1,704 \\
\hline $\mathbf{3}$ & 0,117 & 2,028 & 0,143 & 2,146 \\
\hline $\mathbf{4}$ & 0,109 & 1,898 & 0,678 & 1,520 \\
\hline $\mathbf{5}$ & 0,113 & 1,842 & 0,568 & 2,175 \\
\hline $\mathbf{6}$ & 0,107 & 2,830 & 1,689 & 1,586 \\
\hline $\mathbf{7}$ & 0,128 & 2,766 & 0,599 & 2,091 \\
\hline $\mathbf{8}$ & 0,118 & 5,204 & 9,352 & 1,950 \\
\hline
\end{tabular}

Parâmetros de referência: Portaria MS no 2914 de 12/12/2011

VMP: Valor Máximo Permitido

Fonte: dos autores.

Vários estudos relatam correlações significativas entre indicadores de poluição hídrica e bactérias patogênicas gastrointestinais. A presença de organismos patogênicos na água é um indicador de poluição, pois do contrário, a ausência de microrganismos patogênicos é evidência de uma água bacteriologicamente potável (SIQUEIRA et al., 2010).

Uma importante fonte de contaminação das águas superficiais e subterrâneas são as águas de drenagem oriundas de áreas agrícolas, pastagens e áreas urbanas. O potencial risco de contaminação de águas de poços requer atenção especial, visto que o movimento de resíduos animais em águas de superfície pode ser um fator importante que contribui para a poluição da água disponível em muitas regiões (CABRAL, 2010).

No estudo de Siqueira (2010) realizado com água de cisternas, foi observado que $62,5 \%$ das amostras analisadas apresentaram coliformes totais e $42,5 \%$ das águas pesquisadas apresentaram positividade para coliformes termotolerantes.

Rohden et al. (2009) verificaram resultados alarmantes quanto à contaminação hídrica em água de poços, em um município no estado de Santa Catarina, destinadas ao consumo humano e sem tratamento prévio. Os autores puderam ainda relacionar tal contaminação ao descaso com os cuidados de preservação da natureza, água de poços, rios, fontes, entre outros.

Malheiros et al. (2009), também em um município do estado de Santa Catarina, verificaram que a contaminação bacteriológica de água de poços, estava relacionada à 
presença de lavouras e criação de animais próximo às fontes de água, e também pela proteção inadequada dos poços.

A determinação de microrganismos intestinais como indicadores de contaminação fecal é um princípio aceito no monitoramento e avaliação de segurança em sistemas de abastecimento de água. Conforme demonstrados na Tabela 4, todas as amostras apresentaram resultado de coliformes totais, coliformes termotolerantes e bactérias heterotróficas acima do padrão legal vigente, conforme estipulado pela Portaria MS no 2914 de 12/12/2011 (BRASIL, 2011).

Tabela 4 - Análise microbiológica de águas superficiais em município do interior do Rio Grande do Sul

\begin{tabular}{c|c|c|c}
\hline Amostra & $\begin{array}{c}\text { Contagem Total de Heterotróficos } \\
\text { Valor Máximo Permitido: 500 } \\
\text { UFC/mL }\end{array}$ & $\begin{array}{c}\text { Coliformes Totais } \\
\text { Valor Máximo Permitido: }<\text { 3,0 } \\
\text { NMP/g (Ausência) }\end{array}$ & $\begin{array}{c}\text { Coliformes Termotolerantes } \\
\text { Valor Máximo Permitido: }<\mathbf{3 , 0} \\
\text { NMP/g (Ausência) }\end{array}$ \\
\hline $\mathbf{1}$ & $>1000$ & $>110$ & $>110$ \\
\hline $\mathbf{2}$ & $>1000$ & $>110$ & $>110$ \\
\hline $\mathbf{3}$ & $>1000$ & $>110$ & $>110$ \\
\hline $\mathbf{4}$ & $>1000$ & $>110$ & $>110$ \\
\hline $\mathbf{5}$ & $>1000$ & $>110$ & $>110$ \\
\hline $\mathbf{6}$ & $>1000$ & $>110$ & $>110$ \\
\hline $\mathbf{7}$ & $>1000$ & $>110$ & $>110$ \\
\hline $\mathbf{8}$ & $>1000$ & Instrução Normativa $\mathrm{n}^{\circ}$ 62 de 26/08/2003 DAS/MAPA \\
\hline \multicolumn{2}{|c}{} \\
\hline
\end{tabular}

Fonte: dos autores.

A portaria MS n ${ }^{\circ} 2914$, de 2011, também recomenda que nos casos de elevada contagem de bactérias heterotróficas, deva ser realizado uma investigação para que possa ser identificada a irregularidade e estabelecido o plano de ações a ser adotadas para o restabelecimento da integridade do sistema de fornecimento de água, recomendando que não se ultrapasse o limite de $500 \mathrm{UFC} / \mathrm{mL}^{3}$. No caso das amostras analisadas neste objeto de estudo, todas apresentaram contagem de bactérias heterotróficas acima de $1000 \mathrm{UFC} / \mathrm{mL}$.

A mesma portaria acima citada, correlaciona a necessidade de atendimento do padrão de turbidez com vistas à garantia bacteriológica da água, não ultrapassando o VMP de 5,0 uT ${ }^{3}$.

Tais resultados obtidos estão em conformidade com o descrito no estudo realizado por Domingues et al. (2007), quando das 11 amostras de águas provenientes de poços rasos da região de Santa Maria, no Estado do Rio Grande do Sul, nove amostras 
evidenciaram mais de $500 \mathrm{UFC} / \mathrm{mL}$ de bactérias heterotróficas, correlacionando ainda o resultado às condições do poço, como profundidade, tipo de captação e distância entre o poço e a fossa sanitária.

Em todas as amostras identificou-se presença de coliformes totais e coliformes termotolerantes acima do padrão legal estipulado. Resultado simular foi obtido por Colvara et al. (2009), em estudo de avaliação de contaminação de águas subterrâneas e poços artesianos em cinco municípios do Estado do Rio Grande do Sul, onde todas as amostras apresentavam coliformes totais e $70 \%$ estavam contaminadas com coliformes termotolerantes.

Os resultados obtidos revelam a deficiência das águas captadas para consumo humano e animal, e demonstra o elevado risco de consumo à saúde, visto que diversas doenças estão associadas à veiculação hídrica, tais como amebíase, giardíase, gastroenterite, febres tifoide e paratifoide, hepatite infecciosa, cólera, além de a água estar ligada a transmissão de verminoses como esquistossomose, ascaridíase, teníase, oxiuríase e ancilostomíase (WHO, 1996).

Tais resultados decorrem de condições inadequadas de manejo ambiental, ausência de cuidados com a fonte da água, limpeza dos poços, inadequada localização da captação, manejo de dejetos animais, e falta ou inadequada orientação e conscientização dos consumidores.

Assim, como demonstrado em diversos estudos referenciados neste objeto de pesquisa, a ausência de políticas públicas, e, principalmente, orientação de direito que deveria ser repassada pela autoridade de saúde pública municipal e estadual, expõem desnecessariamente ao risco uma parcela da sociedade que permanece esquecida em áreas rurais deste país.

Além disso, pode estar relacionado a esses resultados o fator cultural, uma vez que a maior parcela destas propriedades é abastecida por rede geral de água. Assim, alguns questionamentos surgem: por que apesar do acesso à água potável, esses cidadãos preferem consumir água de fonte? No imaginário desses indivíduos: a água de fonte seria mais saudável e "inócua" se comparada à advinda da rede geral? Outro fator importante que provavelmente influencia no uso da água de fonte é o custo, uma vez que a água oriunda da rede geral deve ser paga, então: por que pagar por um recurso que está disponível gratuitamente na propriedade? A partir destes questionamentos, surgem alguns específicos para nós profissionais da saúde, educação e ambiente, entre eles: onde temos falbado na educação de nossos cidadãos quanto a aspectos higiênico-sanitários fundamentais, que faz com que, em pleno século XXI, ainda convivamos com as doenças de Jeca Tatu?

\section{CONCLUSÃO}

A totalidade das amostras apresentaram resultado de turbidez, cor, coliformes totais, coliformes termotolerantes e bactérias heterotróficas acima do padrão legal e 
nitrato dentro dos padrões preconizados pela legislação. Conclui-se com este estudo que as águas testadas se apresentaram inadequadas ao consumo humano.

\section{AGRADECIMENTOS}

Aos proprietários das áreas onde foram realizadas as coletas pela concordância com a realização da pesquisa e à Secretaria Municipal de Saúde do município amostrado pelo auxílio na coleta das amostras de água.

\section{REFERÊNCIAS}

ALABURDA, J; NISHIHARA, L. The occurrence of nitrogen compounds in well water. Revista Saúde Pública, n. 32, v. 2, p. 160-165, 1998.

\section{AMERICAN PUBLIC HEALTH ASSOCIATION. Standard methods for the examination of water \& wastewater. Washington DC: APHA, 2005.}

BRASIL. Ministério da Agricultura, Pecuária e Abastecimento. Secretaria de Defesa Agropecuária. Instrução Normativa no 62, de 26 de agosto de 2003. Oficializa os Métodos Analíticos Oficiais para Análises Microbiológicas para Controle de Produtos de Origem Animal e Água. Diário Oficial da União, set. 2003.

BRASIL. Portaria Ministério da Saúde no 2914 de 12 de dezembro de 2011. Dispõe sobre os procedimentos de controle e de vigilância da qualidade da água para consumo humano e seu padrão de potabilidade. Diário Oficial da União, jan. 2012.

BRASIL. Programa nacional de desenvolvimento de recursos hídricos. Brasília: Ministério da Integração Nacional, Ministério do Meio Ambiente, Agência Nacional de Águas. Manual Operativo. v. 1, set. 2009.

BRASIL. Programa nacional de vigilância em saúde ambiental relacionada à qualidade da água para consumo humano. Brasília: Ministério da Saúde, Secretaria de Vigilância em Saúde. Coordenação Geral de Vigilância em Saúde Ambiental. abr. 2004.

CABRAL, J. P. S. Water Microbiology. Bacterial Pathogens and Water. International Journal of Environmental Research and Public Health. v. 7, n. 10, p. 3657-3703, 2010.

CENTRO UNIVERSITÁRIO UNIVATES. Vale do Taquari. Disponível em: <http:// www.univates.br/institucional/vale-do-taquari>. Acesso em: 8 set. 2012.

CHOW, V. T.; MAIDMENT, D. R.; MAYS, L. W. Applied Hydrology. New York: Mcgraw Hill Book Company, 1988.

CLEMENTINO, M. R. A.; NETO, P. J. R.; ALENCAR, J. R. B. Total organic carbon: analytical methodology and its applications in pharmaceutical industry. Revista Brasileira de Farmácia, v. 89, n. 1, p. 74-80, 2008. 
COLVARA, J. G.; LIMA, A. S.; SILVA, W. P. Avaliação da contaminação de água subterrânea em poços artesianos no sul do Rio Grande do Sul. Braz.J. Food Technol. p. 1114, 2009.

DOMINGUES, O. V. et al. Heterotrophic bacteria counting in the drinking water: comparation between two methodologies. Saúde, v. 33, n. 1, p. 15-19, 2007.

ESTEVES, F. A. Fundamentos de limnologia. 2. ed. Rio de Janeiro: Interciência, 1998.

HOTEZ, P. The Giant Anteater in the Room: Brazil's Neglected Tropical Diseases Problem. PLoS Neglected Tropical Diseases, v. 2, n. 1, p.177, 2008.

INSTITUTO BRASILEIRO DE GEOGRAFIA E ESTATÍSTICA (IBGE). Censo

Demográfico de 2000. Disponível em: <http://www.sidra.ibge.gov.br/cd/cd2000cgp .asp?o=20\&i=P>. Acesso em: 10 jan. 2015.

INSTITUTO BRASILEIRO DE GEOGRAFIA E ESTATÍSTICA (IBGE). Censo Demográfico de 2010. Disponível em: <http://www.sidra.ibge.gov.br/cd/cd2010 universo. asp?o=7\&i=P >. Acesso em: 10 jan. 2015.

KOLLET, S. J.; MAXWELL, R. M. Integrated surface-groundwater flow modeling: A freesurface overland flow boundary condition in a parallel groundwater flow model. Advances in Water Resources, v. 29, n. 7, p. 945-958, 2006.

LUNA, C. F. et al. Impacto do uso da água de cisternas na ocorrência de episódios diarreicos na população rural do agreste central de Pernambuco, Brasil. Rev. Bras. Saúde Matern.

Infant., v. 11, n. 3, p. 283-292, 2011.

MAIER, M. H. Considerações sobre características limnológicas de ambientes lóticos. Bolm. Inst. Pesca, v. 5, n. 1, p. 75-90, 1978.

MALHEIROS, O. S. et al. Contaminação bacteriológica de águas subterrâneas da região oeste de Santa Catarina, Brasil. Rev. Inst. Adolfo Lutz, v. 68, n. 2, p. 305-308, 2009.

MANTOVANI, J. E.; NOVO, E. M. L. M. Comportamento Espectral da Matéria Orgânica Dissolvida. São Jose dos Campos, SP: INPE - Instituto Nacional de Pesquisas Espaciais, 2010.

MORTATTI, J. Fluxo de carbono inorgânico dissolvido no Rio Piracicaba (São Paulo): partição e reações de equilíbrio do sistema carbonato. São Paulo: Centro de energia nuclear na agricultura, 2006.

PALMA, Ana. Fio da História: Monteiro Lobato e a gênese do Jeca Tatu. Agência Fiocruz de Notícias. Disponível em: <http://www.fiocruz.br/ccs/cgi/cgilua.exe/sys /start. htm?infoid=20\&sid=5>. Acesso em: 7 ago. 2012.

RAMOS, M. H. C. Remoção de cor, ferro e manganês de águas com matéria orgânica dissolvida por pré-oxidação com dióxido de cloro, coagulação e filtração. [Dissertação]. Ribeirão Preto: Programa de Pós-graduação em Tecnologia Ambiental - Universidade de Ribeirão Preto, 2010. 
ROHDEN, F. et al. Monitoramento microbiológico de águas subterrâneas em cidades do Extremo Oeste de Santa Catarina. Ciência \& Saúde Coletiva, v. 14, n. 6, p. 2199-2203, 2009.

SANTOS, P. P. et al. Qualidade microbiológica de afluentes e efluentes de estações de tratamento de água e esgoto de Goiânia, Goiás. Revista de Patologia Tropical, v. 39, n. 3, p. 173-187, 2010.

SÃO PAULO (Estado). Doenças relacionadas à água ou de transmissão hídrica. São Paulo: Divisão de Doenças de Transmissão Hídrica e Alimentar - DDTHA/CVE. Informativo técnico. dez. 2009.

SIQUEIRA, L. P. et al. Avaliação microbiológica da água de consumo empregada em unidades de alimentação. Ciência \& Saúde Coletiva, v. 15, n. 1, p. 63-66, 2010.

SORSAFAWA, M. A. et al. Physico-chemical evalution of drinking water quality human consumption. São Paulo: Instituto Adolf Lutz, 2010.

UNIVERSIDADE FEDERAL DE VIÇOSA. Qualidade da água. Disponível em <www. ufv.br/dea/lqa/qualidade.htm>. Acesso em: 4 set. 2012.

WHO (World Health Organization). Guidelines for Drinking-Water Quality. Geneva: WHO, 1996.

ZILLMER, T. A.; VARELLA, R. F.; ROSSETE, A. N. Evaluation of physico-chemical characteristics of water in the salgadinho stream, Nova Xavantina-MT. Holos Enviromment. v. 7 , n. 2, p. 123-138, 2006. 